\title{
Trends in poisoning hospitalization and mortality in Taiwan, 1999-2008: a retrospective analysis
}

\author{
Wu-Chien Chien ${ }^{1 *}$, Jin-Ding Lin ${ }^{1}$, Ching-Huang Lai ${ }^{1}$, Chi-Hsiang Chung ${ }^{2}$ and Yu-Chen Hung ${ }^{2}$
}

\begin{abstract}
Background: Subjects with non-fatal poisoning may be left with permanent, disabling sequelae, and the resultant long-term use of medical services smay be a burden on the public health care system. The objective of this study was to describe the epidemiology of poisoning in Taiwan from 1999 to 2008.

Methods: We analyzed poisoning-related data of mortality rates sourced from official Taiwanese vital statistics and of hospitalization from the National Health Insurance (NHI) Research Database. The data were age-adjusted to the year 2000 Standard Population to determine 10-year hospitalization and mortality rate trends, which we stratified according to gender, age, and poisoning agent. Poisson regression was used to investigate the trends.

Results: There were 20,260 deaths and 210,021 hospitalizations related to poisoning, with mortality and hospitalization rates of 8.21 per 100,000 and 86.30 per 100,000 population, respectively. Males exhibited higher rates of mortality and hospitalization as a result of poisoning, with the highest risk in those aged 65 years or older. Medicinal drugs followed by pesticides were the two most common agents of poisoning. There was an increasing trend of both poisoning-related mortality and hospitalization rates during the study period, with a greater increase occurring in the hospitalization rate than in the mortality rate.
\end{abstract}

Conclusions: We found the males aged 65 years or older were at highest risk of poisoning, with medicinal drugs being the leading cause. Hospitalization rates increased more than mortality rates over the 10-year period. Appropriate poisoning prevention programs need to be developed. We should strengthen case management and improve access to health services to increase survival in cases of poisoning.

Keywords: poisoning, mortality, hospitalization, trends

\section{Background}

Poisoning is a global public health concern. The World Health Organization (WHO) indicated that in 2000, unintentional poisoning resulted in 315,000 deaths worldwide. This represents $6 \%$ of all deaths from unintentional injuries, a proportion that is comparable with deaths from unintentional falls [1]. According to statistics from the American Association of Poison Control Centers in 2004, one poisoning case occurred every 13 seconds in the United States (US), with an incidence of 5.5-18.1 per 1,000 population. Altogether there was a yearly total of 200,000 cases of suicide poisoning along with two million cases of unintentional poisoning [2].

\footnotetext{
* Correspondence: chienwu@mail.ndmctsgh.edu.tw

'School of Public Health, National Defense Medical Center, No. 161, Section 6, Min-Chuan E. Rd., Neihu, Taipei, 11490, Taiwan

Full list of author information is available at the end of the article
}

Among all unintentional injuries in the US, unintentional poisoning ranks as the second leading cause of death, surpassed only by automobile injuries [3]. According to the US Centers for Disease Control and Prevention, poisoning accounted for the largest increase in mortality rate among all unintentional injuries from 1999 to 2004, with an overall increase of 55.7\%, and a $62.5 \%$ increase in unintentional poisoning, a $10.8 \%$ increase in suicide poisoning, and a $26.6 \%$ increase in unspecified poisoning [4]. In addition, according to health statistics in the United Kingdom, poisoning was the second leading cause of death among all unintentional injuries in England and Wales in 2004, ranked only behind fall injuries. As mortality from suicide poisoning declined between 1979 and 2004, mortality from unintentional and drug abuse poisoning rose to become the primary cause of poisoning [5].

\section{Biomed Central}

(c) 2011 Chien et al; licensee BioMed Central Ltd. This is an Open Access article distributed under the terms of the Creative Commons Attribution License (http://creativecommons.org/licenses/by/2.0), which permits unrestricted use, distribution, and reproduction in any medium, provided the original work is properly cited. 
According to the Taiwan National Poison Center, the incidence of poisoning in Taiwan is about $0.16-0.22$ per 1,000 population [6]. Statistics from the Department of Health showed that a total of 324 Taiwanese subjects died from unintentional poisoning in 2007. The poisoning mortality rate ranks fourth among unintentional injuries, of which the top three causes are automobile injuries, unintentional falls, and drowning [7]. In Taiwan, there was a decreasing trend in poisoning mortality from 1975 to 1998 , with a drop of $41.2 \%$. While unintentional and intentional poisoning mortality fell by $40.1 \%$ and $55.6 \%$, respectively, there was a 32.5 -fold increase in the mortality from unspecified poisoning [8]. In addition, a study showed that between 1986 and 2005, suicides using solid or liquid substances and suicides using gas and vapor were the second and third leading agents of suicide deaths [9].

Most previous studies conducted in Taiwan that focused on poisoning were cross-sectional and failed to present the overall epidemiological characteristics and long-term trends in poisoning. Therefore, this study aimed to describe the epidemiological characteristics and trends of poisoning in Taiwan using a combination of cause-of-death statistics and the National Health Insurance (NHI) Research Database containing hospitalization data.

\section{Methods}

\section{Data source}

The mortality data in Taiwan from 1999-2008 were obtained from the cause-of-death statistics provided by the Department of Health, Executive Yuan [7]. Hospitalization data were extracted from the NHI Research Database [10]. Since its launch on March 1, 1995, the NHI has reached a coverage rate of $99 \%$ of hospitals in Taiwan. The NHI Research Database consists of data on both outpatient (including emergency treatment) and inpatient care. Medical institutions are required by law to make claims for outpatient costs and inpatient fees to the NHI Bureau. Hence, the NHI Research Database is an essential resource of representative and evidencebased data for studies in medical and health research, which may play a valuable role in future health policy [10].

Our research required secondary data analysis, and the identification of patients had already been encrypted in the official death statistics and the NHI Research Database in Taiwan; therefore, our research complied with the Helsinki Declaration and protected the privacy of patients.

\section{Data analysis}

We calculated the mortality and hospitalization rates using the mid-year population in the "population by age report" provided by the Ministry of the Interior as the denominator. Data were age-adjusted by the direct method to the 2000 World Standard population obtained from the WHO. Afterwards, we calculated the 10 -year trends in poisoning mortality and hospitalization rates and stratified them by gender, age, and causative agent.

The Department of Health age classification, which uses 6 groupings, was adopted as follows: infants and toddlers, aged 0-4 years; children, aged 5-14 years; young adults, aged 15-24 years; mature adults, aged 2544 years; middle-aged adults, aged $45-64$ years; and the elderly, aged 65 years or older. The official death statistics and NHI database employ the ICD-9-CM coding system in Taiwan, so we selected study cases by ICD-9CM external causes of injury codes (E-Codes), which include "unintentional poisoning, such as by medicinal drugs (E850-E858), alcohol (E860), cleaning solutions (E861), petroleum products (E862), pesticides (E863), corrosives (E864), foodstuffs (E865), other solid and liquid substances (E866), gas distributed by pipeline (E867), carbon monoxide (E868), other gases and vapors (E869), venomous animals and plants (E905), and medicinal drugs causing adverse effects (E930-E948)"; "intentional poisoning, such as suicide using solid or liquid substances (E950), suicide using gases in domestic use (E951), suicide using other gases and vapors (E952), and assault using poisoning (E962)"; and "substances, undetermined whether accidently or purposely inflicted (E980), by unspecified gases in domestic use (E981), and by other unspecified gases (E982)."

For statistical analysis, the independent sample Student t-test, one-way analysis of variance, and Scheffe's post hoc comparisons were conducted using SPSS 18.0 software to examine the differences in poisoning mortality and hospitalization rates according to gender, age, and poisoning agent. Poisson regression was used to identify 10-year trends.

\section{Results}

\section{Epidemiological characteristics}

Between 1999 and 2008, there were a total of 20,620 deaths from poisoning in Taiwan, representing a mortality rate of 8.21 per 100,000 population. When considering intent, the number of deaths caused by intentional poisoning was the greatest, with 14,440 deaths $(70.03 \%$ of all poisoning deaths), and demonstrated the highest mortality rate (5.73 per 100,000 population). The second and third greatest causes of poisoning deaths were unintentional poisoning $(17.41 \% ; 1.45 / 100,000)$ and unspecified poisoning (12.56\%; 1.03/100,000). Men demonstrated a mortality rate 2.3 times higher than women (11.46 versus 4.92 per 100,000 population). Cross-analysis of gender and intention showed that men 
had a higher proportion of unintentional poisoning among all poisoning deaths than women $(18.71 \%$ versus $14.29 \%$ ), whereas women had higher proportions of intentional and unspecified poisoning among all poisoning deaths than men $(72.77 \%$ versus $68.88 \%$ and $12.94 \%$ versus $12.41 \%$, respectively). Cross-analysis of age and intention showed that death from unintentional poisoning was significantly higher in the 25-44 year and 65 years or older age groups (2.59 and 2.18 per 100,000 , respectively) compared with other age groups; on the other hand, mortality rates from intentional poisoning were significantly higher in the 65 years or older, 45-64, and 25-44 year age groups $(10.63,9.44$, and 8.86 per 100,000 , respectively) compared with other age groups (Table 1).

A cross-analysis of gender and intention revealed that the proportion of unintentional poisoning in hospitalized male patients was higher than in their female counterparts $(76.42 \%$ versus $69.11 \%)$, while the proportions of intentional and unspecified poisoning were higher in hospitalized female patients than in their male counterparts (21.24\% versus $15.19 \%$ and $9.64 \%$ versus $8.39 \%$, respectively). With regard to hospitalization rate, men demonstrated a 1.04 times higher rate of hospitalization for poisoning than women (88.03 versus 84.78 per 100,000). A cross-analysis of age and intention showed that the 65 years or older and 45-64 year age groups had significantly higher rates of hospitalization for unintentional poisoning (291.58 and 90.87 per 100,000 , respectively), and subjects aged 65 years or older demonstrated the highest rate of hospitalization for intentional poisoning (27.26 per 100,000) (Table 2).

\section{Long-term trends}

Between 1999 and 2008, there was an increasing trend in overall poisoning mortality rate with a significant $47.2 \%$ increase $(p=.002)$. Men demonstrated a larger increase in mortality rate than women during this time ( $57.6 \%$ versus $26.2 \%, p=.001$ and .012 , respectively) (Figure 1a). There was also a rising trend in overall poisoning hospitalization rate, with a $79.1 \%$ increase, $p<$ .001. Men had a larger increase in hospitalization rate than women (98.1\% versus $61.4 \%, p<.001$ and $p=.001$, respectively) (Figure $1 \mathrm{~b}$ ).

The population aged 65 years or older demonstrated a declining trend in mortality with a drop of $19.9 \%$ over the 10 -year period $(p<.001)$. However, the $25-44$ year age group showed a rising trend in mortality rate, with a $120.7 \%$ increase $(p<.001)$, and in 2005 , the rate in this group surpassed that of subjects aged 65 years or older to become the primary high-risk group for poisoning (Figure 2a). Considering hospitalization, the age

Table 1 Poisoning mortality rates by gender and age in Taiwan in 1999-2008 (per 100,000 population)

\begin{tabular}{|c|c|c|c|c|c|c|c|c|c|c|c|c|c|c|c|}
\hline \multirow[t]{2}{*}{ Types } & \multirow{2}{*}{$\begin{array}{c}\text { Age } \\
\text { Gender }\end{array}$} & \multicolumn{2}{|c|}{ (1) $0-4$ yrs } & \multicolumn{2}{|c|}{ (2) $5-14$ yrs } & \multicolumn{2}{|c|}{ (3) $15-24$ yrs } & \multicolumn{2}{|c|}{ (4) $25-44$ yrs } & \multicolumn{2}{|c|}{ (5) $45-64$ yrs } & \multicolumn{2}{|c|}{ (6) $\geqq 65$ yrs } & \multicolumn{2}{|c|}{ Total } \\
\hline & & $\mathrm{N}$ & Rate & $\mathrm{N}$ & Rate & $\mathrm{N}$ & Rate & $\mathrm{N}$ & Rate & $\mathrm{N}$ & Rate & $\mathrm{N}$ & Rate & $\mathrm{N}$ & Rate \\
\hline Unintentional Poisoning $* * *$ & Total & 38 & 0.29 & 56 & 0.18 & 329 & 0.89 & 1,939 & 2.59 & 766 & 1.56 & 460 & 2.18 & 3,589 & 1.45 \\
\hline \multirow[t]{2}{*}{ (4),(6) $>$ (5) $>$ (3),(1), (2) } & Male & 15 & 0.22 & 35 & 0.21 & 215 & 1.13 & 1,562 & 4.12 & 622 & 2.54 & 268 & 2.55 & 2,718 & 2.16 \\
\hline & Female & 23 & 0.36 & 21 & 0.14 & 114 & 0.63 & 377 & 1.02 & 144 & 0.58 & 192 & 1.83 & 871 & 0.73 \\
\hline Drugs *** & Total & 4 & 0.03 & 1 & $<0.01$ & 181 & 0.48 & 1,129 & 1.52 & 181 & 0.35 & 70 & 0.33 & 1,566 & 0.63 \\
\hline (E850-E858) & Male & 1 & 0.02 & 1 & 0.01 & 121 & 0.63 & 953 & 2.53 & 155 & 0.62 & 38 & 0.36 & 1,269 & 0.99 \\
\hline (4) $>$ (3), (5),(6) $>$ (1), (2) & Female & 3 & 0.05 & 0 & 0 & 60 & 0.33 & 176 & 0.48 & 26 & 0.10 & 32 & 0.31 & 297 & 0.25 \\
\hline Other utility gas and $\mathrm{CO}$ ** & Total & 26 & 0.20 & 48 & 0.15 & 87 & 0.24 & 295 & 0.39 & 134 & 0.27 & 56 & 0.27 & 646 & 0.27 \\
\hline (E868) & Male & 9 & 0.13 & 32 & 0.19 & 46 & 0.25 & 196 & 0.52 & 99 & 0.40 & 36 & 0.33 & 418 & 0.34 \\
\hline (4) $>$ (5), (6, (3), (1), (2) & Female & 17 & 0.27 & 16 & 0.11 & 41 & 0.23 & 99 & 0.27 & 35 & 0.14 & 20 & 0.20 & 228 & 0.20 \\
\hline Pesticide ${ }^{* * *}$ & Total & 1 & 0.01 & 0 & 0 & 27 & 0.08 & 164 & 0.22 & 206 & 0.44 & 196 & 0.93 & 594 & 0.24 \\
\hline (E863) & Male & 1 & 0.01 & 0 & 0 & 24 & 0.13 & 134 & & 170 & 0.74 & 128 & 1.21 & 457 & 0.37 \\
\hline (6) $>$ (5), (4), (3), (1), (2) & Female & 0 & 0 & 0 & 0 & 3 & 0.02 & 30 & 0.08 & 36 & 0.15 & 68 & 0.65 & 137 & 0.11 \\
\hline Intentional poisoning $* * *$ & Total & 25 & 0.19 & 29 & 0.09 & 840 & 2.24 & 6,708 & 8.86 & 4,578 & 9.44 & 2,260 & 10.63 & 14,440 & 5.73 \\
\hline \multirow[t]{2}{*}{ (6), (5, (4) > (3), (1), (2) } & Male & 11 & 0.16 & 10 & 0.06 & 567 & 2.94 & 4,829 & 12.59 & 3,279 & 13.59 & 1,308 & 12.23 & 10,004 & 7.88 \\
\hline & Female & 14 & 0.22 & 19 & 0.13 & 273 & 1.51 & 1,879 & 5.03 & 1,299 & 5.34 & 952 & 9.01 & 4,436 & 3.56 \\
\hline Not explicitly $* * *$ & Total & 11 & 0.09 & 14 & 0.04 & 158 & 0.42 & 1,244 & 1.65 & 703 & 1.44 & 461 & 2.18 & 2,591 & 1.03 \\
\hline \multirow[t]{2}{*}{ (6) $>$ (4), (5) > (3), (1), (2) } & Male & 8 & 0.12 & 6 & 0.04 & 98 & 0.51 & 939 & 2.45 & 507 & 2.09 & 244 & 2.27 & 1,802 & 1.42 \\
\hline & Female & 3 & 0.05 & 8 & 0.05 & 60 & 0.33 & 305 & 0.82 & 196 & 0.80 & 217 & 2.08 & 789 & 0.64 \\
\hline Total *** & Total & 74 & 0.57 & 99 & 0.31 & 1,327 & 3.55 & 9,891 & 13.10 & 6,047 & 12.43 & 3,155 & 14.98 & 20,620 & 8.21 \\
\hline \multirow[t]{2}{*}{$(6,4,45>$ (3) $>$ (1), (2) } & Male & 34 & 0.50 & 51 & 0.31 & 880 & 4.57 & 7,330 & 19.16 & 4,408 & 18.21 & 1,809 & 17.04 & 14,524 & 11.46 \\
\hline & Female & 40 & 0.63 & 48 & 0.32 & 447 & 2.47 & 2,561 & 6.88 & 1,639 & 6.71 & 1,346 & 12.96 & 6,096 & 4.92 \\
\hline
\end{tabular}

The data show only the top 3 agents of unintentional poisoning

ANOVA $\left({ }^{*} p<.05 ;{ }^{* *} p<.01 ;{ }^{* *} p<0.001\right)$, Scheffe's post hoc comparisons 
Table 2 Poisoning hospitalization rates by gender and age in Taiwan in 1999-2008 (per 100,000 people)

\begin{tabular}{|c|c|c|c|c|c|c|c|c|c|c|c|c|c|c|c|}
\hline \multirow[t]{2}{*}{ Types } & \multirow{2}{*}{$\begin{array}{c}\text { Age } \\
\text { Gender }\end{array}$} & \multicolumn{2}{|c|}{ (1) $0-4$ yrs } & \multicolumn{2}{|c|}{ (2) $5-14$ yrs } & \multicolumn{2}{|c|}{ (3) $15-24$ yrs } & \multicolumn{2}{|c|}{ (4) $25-44$ yrs } & \multicolumn{2}{|c|}{ (5) $45-64$ yrs } & \multicolumn{2}{|c|}{ (6) $\geqq 65$ yrs } & \multicolumn{2}{|c|}{ Total } \\
\hline & & $\mathrm{N}$ & Rate & $\mathrm{N}$ & Rate & $\mathrm{N}$ & Rate & $\mathrm{N}$ & Rate & $\mathrm{N}$ & Rate & $\mathrm{N}$ & Rate & $\mathrm{N}$ & Rate \\
\hline Unintentional Poisoning*** & Total & 5,455 & 42.50 & 3,733 & 11.90 & 9,026 & 24.67 & 30,047 & 39.52 & 42,670 & 90.87 & 62,114 & 291.58 & 153,045 & 63.31 \\
\hline \multirow[t]{2}{*}{ (6) $>$ (5) $>$ (1), (4), (3), (2) } & Male & 3,034 & 45.28 & 2,152 & 13.19 & 4,696 & 24.94 & 16,427 & 42.59 & 23,479 & 101.20 & 32,724 & 301.99 & 2,512 & 67.61 \\
\hline & Female & 2,421 & 39.46 & 1,581 & 10.51 & 4,330 & 24.39 & 13,620 & 36.36 & 19,191 & 80.81 & 29,390 & 281.02 & 70,533 & 58.98 \\
\hline Drugs *** & Total & 1,943 & 14.86 & 398 & 1.27 & 2,360 & 6.40 & 6,303 & 8.40 & 4,363 & 9.19 & 7,563 & 35.39 & 22,930 & 9.77 \\
\hline (E850-E858) & Male & 1,006 & 14.70 & 220 & 1.35 & 951 & 5.00 & 2,714 & 7.15 & 2,047 & 8.79 & 3,580 & 32.87 & 10,518 & 8.88 \\
\hline (6) $>$ (1) $>$ (5), (4), (3) $>$ (2) & Female & 937 & 15.04 & 178 & 1.18 & 1,409 & 7.88 & 3,589 & 9.69 & 2,316 & 9.61 & 3,983 & 37.91 & 12,412 & 10.68 \\
\hline Animals and $\mathrm{pl}$ & Total & 179 & 1.39 & 353 & 1.12 & 634 & 1.73 & 2,757 & 3.61 & 3,479 & 7.31 & 1,03 & 15 & 05 & 3.85 \\
\hline (E905) & Male & 111 & 1.64 & 237 & 1.44 & 08 & 2.69 & 2,137 & 5.53 & 2,352 & 93 & 54 & 10.97 & 9 & 5.32 \\
\hline (6) $>$ (5) $>$ (4) $>$ (3), (1), (2) & Female & 68 & 1.11 & 116 & 0.77 & 126 & 0.71 & 620 & 1.64 & 1,127 & 4.73 & 749 & 7.31 & 2,806 & 2.36 \\
\hline Pesticide ${ }^{* *}$ & Total & 200 & 1.34 & 53 & 0.17 & 241 & 0.68 & 1,588 & 2.08 & 2527 & 5.44 & 1,709 & 8.25 & 6,328 & 2.62 \\
\hline (E863) & Male & 131 & 1.63 & 33 & 0.20 & 188 & 0.99 & 1,186 & 3.08 & 1878 & 8.24 & 1,249 & 12.01 & 4,666 & 3.85 \\
\hline (6) $>$ (5) $>$ (4) $>$ (1), (3), (2) & Female & 69 & 1.02 & 20 & 0.13 & 63 & 0.35 & 402 & 1.06 & 648 & 2.71 & 460 & 4.45 & 1,662 & 1.38 \\
\hline Intentional poisoning $* * *$ & Total & 66 & 0.51 & 204 & 0.64 & 3,249 & 16.89 & 17,114 & 22.78 & 8,681 & 17.79 & 5,770 & 27.26 & 38,084 & 15.39 \\
\hline \multirow[t]{2}{*}{ (6),(4),(5) > (3),(2), (1) } & Male & 44 & 0.65 & 65 & 0.39 & 2,549 & 13.35 & 6,753 & 17.72 & 4,137 & 17.31 & 2,856 & 26.58 & 16,404 & 13.14 \\
\hline & Female & 22 & 0.36 & 139 & 0.90 & 3,700 & 20.64 & 10,361 & 27.98 & 4,544 & 18.30 & 2,914 & 28.04 & 21,680 & 17.74 \\
\hline Not explicitly $* * *$ & Total & 278 & 2.17 & 215 & 0.68 & 1,862 & 5.06 & 5,723 & 7.59 & 4,455 & 9.33 & 6,359 & 29.82 & 18,892 & 7.66 \\
\hline \multirow[t]{2}{*}{ (6) $>$ (4), (5) > (3), (1), (2) } & Male & 160 & 2.40 & 100 & 0.61 & 805 & 4.25 & 2,636 & 6.89 & 2,236 & 9.52 & 3,116 & 28.79 & 9,053 & 7.28 \\
\hline & Female & 118 & 1.91 & 115 & 0.76 & 1,057 & 5.92 & 3,087 & 8.30 & 2,219 & 9.16 & 3,243 & 30.89 & 9,839 & 8.06 \\
\hline Total $* * *$ & Total & 5,799 & 45.18 & 4,152 & 13.22 & 17,137 & 46.62 & 52,884 & 69.89 & 55,806 & 117.99 & 74,243 & 348.67 & 210,021 & 86.36 \\
\hline \multirow[t]{2}{*}{ (6), (4), (5) > (3) > (1), (2) } & Male & 3,238 & 48.33 & 2,317 & 14.19 & 8,050 & 42.54 & 25,816 & 67.21 & 29,852 & 128.03 & 38,696 & 357.35 & 107,969 & 88.03 \\
\hline & Female & 2,561 & 41.74 & 1,835 & 12.17 & 9,087 & 50.95 & 27,068 & 72.65 & 25,954 & 108.27 & 35,547 & 339.96 & 102,052 & 84.78 \\
\hline
\end{tabular}

The data show only the top 3 agents of unintentional poisoning

ANOVA ( $\left.{ }^{*} p<.05 ;{ }^{* *} p<.01 ;{ }^{* * *} p<0.001\right)$, Scheffe's post hoc comparisons

group of 65 years or older demonstrated the largest rise in hospitalization rate, with an increase of $165.7 \%$ ( $p<$ .001 ), followed by the 45-64 and 25-44 year age groups, with increases of $96.1 \%$ and $30.8 \%$, respectively $(p<.001$ and .055 , respectively) (Figure $2 \mathrm{~b}$ ).

Mortality from unintentional poisoning declined by $35.8 \%$ between 1999 and $2008(p<.001)$. While mortality from intentional poisoning showed an increase of $120.0 \%$ ( $p=.001)$, mortality from unspecified poisoning decreased by $42.7 \%$, but it failed to reach statistical significance $(p=.396)$ (data not shown). There was a
$123.1 \%$ rise in the unintentional poisoning hospitalization rate $(p<.001)$, which was in line with the overall hospitalization rate. While the intentional poisoning hospitalization rate decreased by $23.3 \%(p=.151)$, the unspecified poisoning hospitalization rate increased by $54.1 \%(p<.001)$ (data not shown).

After analyzing the causes of unintentional poisoning, we found that the primary agent of unintentional poisoning was medicinal drugs, followed by carbon monoxide, and pesticides. While most causes of unintentional poisoning demonstrated a decreasing trend in mortality

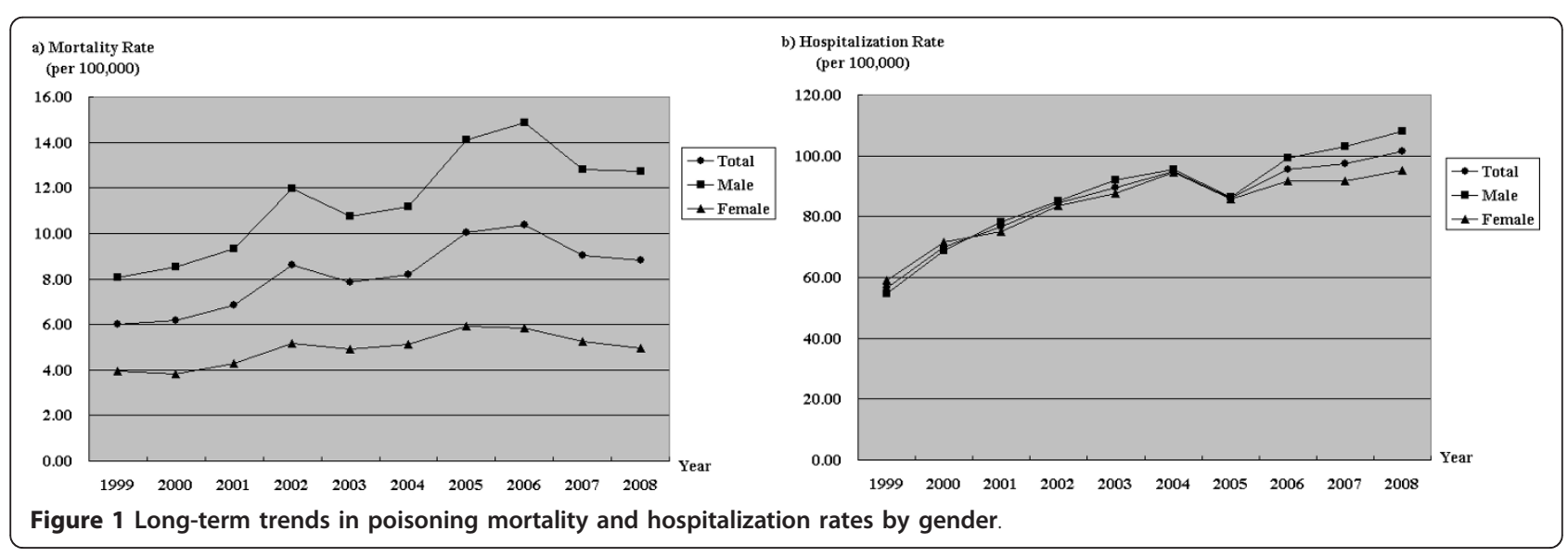




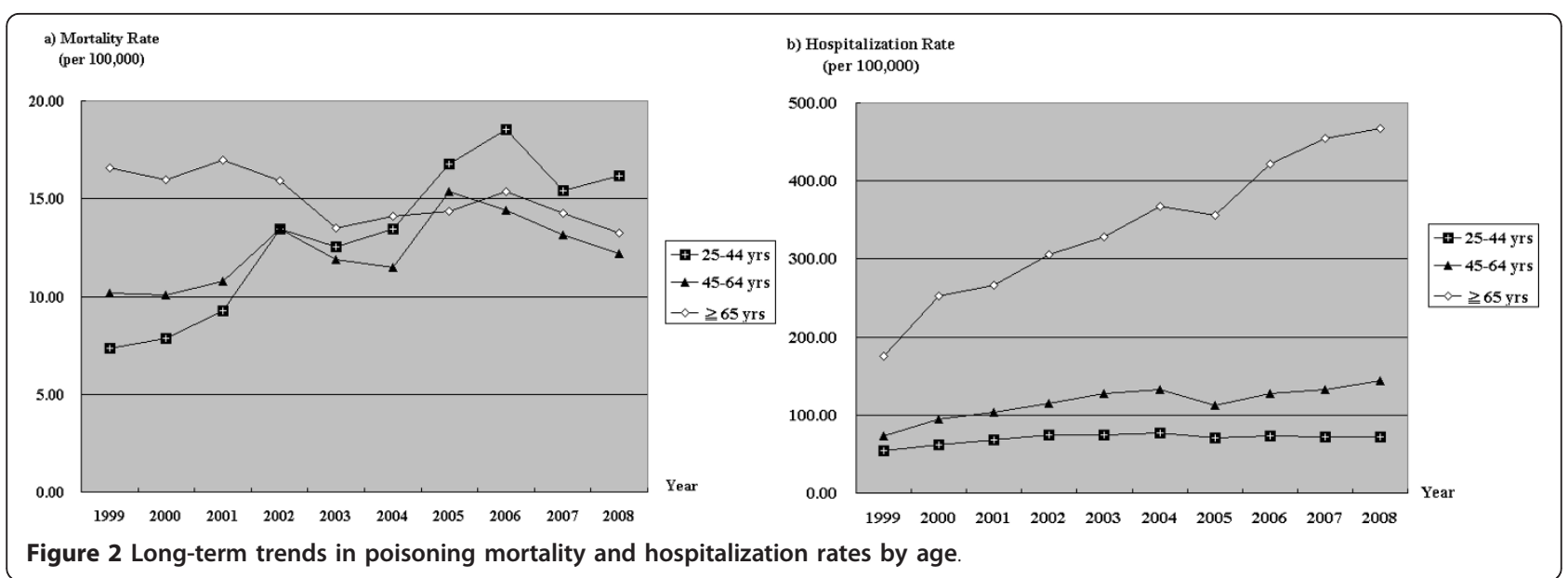

rate, unintentional poisoning by medicinal drugs showed a $51.9 \%$ increase $(p<.001)$ (Figure 3a). Unintentional poisoning by medicinal drugs constituted the leading cause of hospitalization due to unintentional poisoning, followed by venomous animals and plants, and pesticides. In consideration of trends in hospitalization rates, different methods of unintentional poisoning showed varying 10-year trends (Figure 3b).

\section{Discussion}

\section{Poisoning mortality and hospitalization by gender}

Our analysis of overall poisoning mortality revealed that men had higher poisoning mortality than women, regardless of intention; this finding is consistent with the 2000 WHO report that indicated a higher global mortality from unintentional poisoning in men [1]. As for hospitalization, we found that men had a higher rate of hospitalization resulting from unintentional poisoning, and women had a higher rate of hospitalization resulting from intentional poisoning; our findings differed somewhat from the previous literature. In the US, both the 2001-2003 health statistics from Colorado [11], and a study on emergency care data from 2001-2004 [12] indicated a higher poisoning hospitalization rate in women than in men, regardless of intention.

\section{Poisoning mortality and hospitalization by age}

We found that older adults aged 65 years or older showed the highest poisoning mortality among all age groups, regardless of intention. Corresponding to our finding, the $2000 \mathrm{WHO}$ report also demonstrated that subjects aged 80 years or older worldwide had the highest mortality rate from unintentional poisoning, followed by subjects in the 45-59 and 60-69 year age groups [1]. On the other hand, our study was similar to previous research in a hospital center in Taiwan, which showed that the mortality risk in subjects aged 60 and older was 4.3 times more than in those aged under 60 [13]. However, some studies found different trends from ours. In China, a hospital-based study found that the highest rates of poisoning mortality were in adults aged 30-39 years [14]. In south India, a study of poisoning suicide showed that youths aged 20-29 had the highest mortality rate [15]. Regarding poisoning mortality trends, our

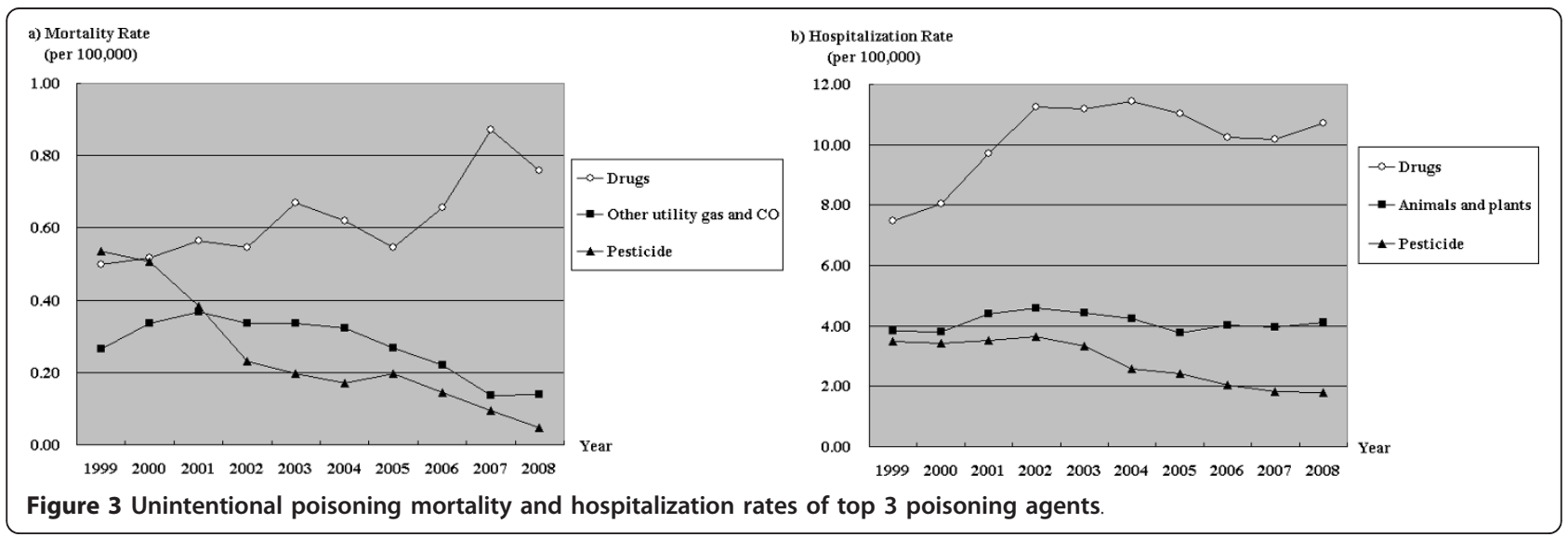


study found that the population aged 65 years or older demonstrated a significantly declining trend in mortality; the results were similar to the European study of Petridou et al. [16].

Older adults aged 65 years or older demonstrated the highest poisoning hospitalization rate among all age groups, regardless of intention; this finding was different from previous literature. The 2001-2003 health statistics in Colorado in the US suggested that adolescents aged 15-19 years were at highest risk of hospitalization for intentional poisoning, with 98.1 cases per 100,000 subjects [11]. On the other hand, an epidemiological study using emergency care data from 2001 to 2004 in Sri Lanka revealed that adolescents aged 15-19 years demonstrated the highest incidence of non-lethal intentional poisoning (248 per 100,000 subjects), a rate that decreased with age [17]. However, our study was similar to previous research that showed the elderly aged 65 or older had the highest medicinal drug poisoning hospitalization rate [18]. The phenomenon may be related to the fact that this population is less well educated and has a lower literacy rate, resulting in a lack of knowledge and skills related to handling items safely. In addition, the existence of multiple illnesses, multiple drug medication and poor physical conditions may also increase the risk of hospitalization or mortality as a result of poisoning.

\section{Poisoning mortality and hospitalization by intention}

The majority of unintentional poisoning deaths was caused by medicinal drugs, followed by carbon monoxide, and pesticides. The most frequent cause of unintentional poisoning hospitalization was medicinal drugs, followed by venomous animals and plants, and pesticides. A number of previous studies showed similar results that medicinal drugs $[11,19-21]$ and pesticides [13-15] were the primary causes of poisoning-related mortality and hospitalization. This phenomenon may result from the widespread prescribing and easy availability of medicinal drugs and pesticides, compared with other poisoning methods. Therefore, the following discussion will focus on the long-term trends in poisoning from medicinal drugs and pesticides.

\section{Trends in mortality and hospitalization from poisoning by medicinal drugs}

This study revealed a rising trend in mortality and hospitalization rates from unintentional poisoning caused by medicinal drugs. This result was similar to a previous study in Taiwan showing an increase in unintentional drug poisoning mortality rate of $51.9 \%$ [18]. Since the launch of the NHI in Taiwan in 1995, the general public has had better access to prescription drugs, such as sleeping pills, sedatives, and analgesics, which may increase the possibility of drug misuse and increase mortality resulting from unintentional drug poisoning [20]. The promulgation of the Drug Harvard Relief Act in Taiwan in 2000 allows timely relief, without resorting to lawsuits or pleads, to victims of unforeseeable adverse reactions from proper use of legal drugs that results in death, disability, or serious illness [21]. Therefore, the launch of the Act may have encouraged reporting of drug poisoning deaths and thus could have increased the death count from unintentional drug poisoning.

\section{Trends in mortality and hospitalization rates from poisoning by pesticides}

This study revealed decreasing trends between 1999 and 2008 in mortality and hospitalization rates from unintentional poisoning by pesticides. In Korea from 1996 to 2005, mortality from pesticides rose for both genders [22]. In Central America, there was also an increase in both incidence and mortality rates of pesticide poisoning from 1992 to 2000, which might be related to increased pesticide imports during the same period of time [23]. In Thailand from 1987 to 1996, both injuries and deaths from pesticide poisoning decreased; however, the numbers might be an underestimation because most locals failed to seek medicinal help in the event of poisoning [24]. In Japan from 1991 to 1996, poisoning by pesticides was on the decline, which could result from the decrease in paraquat poisoning [25].

As a result of social transformations in Taiwan in recent years, the area of farmland has been decreasing. The traditional agriculture-centered Taiwanese society depends more and more on business, traditional industry, and high-technology industry, and organic farming has also gradually replaced traditional farming, resulting in a large decrease in pesticide use. Between 1951 and 1992, the proportion of agricultural workers in the Taiwanese population decreased from $56 \%$ to $12 \%$, while that of industrial workers rose from $16 \%$ to $40 \%$ [26]. According to the 2009 statistics from the Council of Agriculture, Executive Yuan, there has been a decreasing trend in the amount of people employed in the agricultural industry, from approximately 710,000 people in 2002 to about 540,000 people in June, 2009 [27]; this trajectory has coincided with the increasing importance attached to environmental protection and food safety issues by the public. Since 1972, a total of 119 agricultural chemicals have been banned due to high toxicity, teratogenicity after long-term exposure, tumorigenicity, and/or environmental pollution [28]. The abovementioned reasons may well account for the decline in pesticide poisoning mortality rate.

\section{Limitations}

The variables analyzed in this study were limited by the cause-of-death statistics in Taiwan and the 
hospitalization data retrieved from the NHI Research Database. Certain information was not available, such as clinical biochemistry data, education level of subjects, smoking habits, and use of alcohol.

Our study was limited with regards to cause-of-death statistics; when registering the cause of death, the Department of Health only records the first three digits of the E-Codes. The absence of the fourth digit hindered us from extracting additional detailed information. For example, we were unsuccessful in differentiating between organic phosphorus pesticides and organic chlorine pesticides in agricultural chemical poisoning cases and were unable to compare the mortality data against the hospitalization data.

After an injury, posttraumatic care can be categorized into no medical care or self-care, outpatient care, emergency care, inpatient care, and death. However, because the outpatient and emergency treatment data provided by the NHI Research Database failed to include ECodes, we were unable to classify those patients receiving such care by the poisoning method based on the ICD-9-CM system. As a result, only deaths and hospitalized patients for poisoning injuries were analyzed in this study, while those receiving other types of care were excluded.

\section{Conclusions}

Males demonstrated higher rates of poisoning mortality and hospitalization than females in Taiwan between 1999 and 2008. The most affected age group was 65 years or older. The main agents causing death were medicinal drugs, carbon monoxide and pesticides, while the main agents resulting in hospitalization were medicinal drugs, venomous animals/plants, and pesticides. Hospitalization rates increased more than mortality rates over the 10 years.

The results indicated that more attention should be paid to prevention of poisoning in the public health system in Taiwan. In addition, we should adopt the suggestions of Bose et al. [29] to strengthen case management and access to health services to improve survival in cases of poisoning.

\section{Acknowledgements}

This study is based in part on data from the National Health Insurance Research Database provided by the Bureau of National Health Insurance, Department of Health, and managed by National Health Research Institutes. The interpretation and conclusions contained herein do not represent those of the Bureau of National Health Insurance, Department of Health, or National Health Research Institutes.

\section{Author details}

${ }^{1}$ School of Public Health, National Defense Medical Center, No. 161, Section 6, Min-Chuan E. Rd., Neihu, Taipei, 11490, Taiwan. ${ }^{2}$ Graduate Institute of Life Sciences, National Defense Medical Center, No. 161, Section 6, Min-Chuan E. Rd., Neihu, Taipei, 11490, Taiwan.

\section{Authors' contributions}

WCC contributed to the study design, obtained the data and drafted the paper. JDL and CHL provided suggestions for revision of the manuscript. $\mathrm{CHC}$ contributed to analyze the data. YCH contributed to interpretation of the data. All authors have read and approved the final manuscript.

\section{Competing interests}

The authors declare that they have no competing interests.

Received: 12 January 2011 Accepted: 16 September 2011 Published: 16 September 2011

\section{References}

1. World Health Organization: The injury chart book: a graphical overview of the global burden of injuries 2002 [http://whqlibdoc.who.int/publications/ 924156220x.pdf].

2. Watson WA, Litovitz TL, Rodgers GC Jr, Klein-Schwartz W, Reid N, Youniss J, Flanagan A, Wruk KM: 2004 Annual report of the American Association of Poison Control Centers Toxic Exposure Surveillance System. Am J Emerg Med 2005, 23:589-666.

3. Center for Disease Control and Prevention: 10 Leading Causes of Injury Death by Age Group Highlighting Unintentional Injury Deaths, United States-2006. 2009 [http://www.cdc.gov/injury/lmages/LC-Charts/10lc\%20Unintentional\%20Injury\%202006-7_6_09-a.pdf].

4. Paulozzi LJ, Crosby A, Ryan G: Increases in age-group-specific injury mortality-United States, 1999-2004. MMWR Morb Mortal Wkly Rep 2007, 56:1281-1284.

5. Griffiths $C$, Wright $O$, Rooney $C$ : Trends in injury and poisoning mortality using the ICE on injury statistics matrix, England and Wales, 1979-2004. Health Stat Q 2006, 32:5-18.

6. Yang CC, Wu JF, Ong HC, Hung SC, Kuo YP, Sa CH, Chen SS, Deng JF: Taiwan National Poison Center: epidemiologic data 1985-1993. J Toxicol Clin Toxicol 1996, 34:651-663.

7. Department of Health Executive Yuan, ROC (Taiwan): Statistics of causes of death - Number of deaths classified according to the basic tabulation list by gender and age. 2010 [http://www.doh.gov.tw/CHT2006/ DisplayStatisticFile.aspx?d=75924\&s=1].

8. Lu TH: Changes in injury mortality by intent and mechanism in Taiwan, 1975-98. Inj Prev 2002, 8:70-73.

9. Lin JJ, Lu TH: Suicide mortality trends by sex, age and method in Taiwan, 1971-2005. BMC Public Health 2008, 8:6.

10. National Health Research Institutes, ROC (Taiwan): National Health Insurance Research Database. 2010 [http://w3.nhri.org.tw/nhird/index.php].

11. Colorado Department of public and Environment: Injury in Colorado. 2005 [http://www.cdphe.state.co.us/pp/injepi/InjuryinColorado/injuryincolorado. html].

12. Prosser JM, Perrone J, Pines JM: The epidemiology of intentional non-fatal self-harm poisoning in the United States: 2001-2004. J Med Toxicol 2007, 3:20-24.

13. Lee HL, Lin HJ, Yeh ST, Chi CH, Guo HR: Presentations of patients of poisoning and predictors of poisoning-related fatality: findings from a hospital-based prospective study. BMC Public Health 2008, 8:7.

14. Liu Q, Zhou L, Zaheng N, Zhuo L, Lin Y, Liu L: Posioning deaths in China: agent and prevalence detected at the Tongji Forensic Medical Center in Hubei. Forensic Sci Int 2009, 193:88-94.

15. Kanchan T, Menezes RG: Suicidal poisoning in Southern India: gender differences. J Forensic Leg Med 2008, 15:7-14.

16. Petridou ET, Dikalioti SK, Dessypris N, Skalkidis I, Barbone F, Fitzpatrick P, Heloma A, Segui-Gomez M, Sethi D: The evolution of unintentional injury mortality among elderly in Europe. J Agin Health 2008, 20:159-182.

17. Eddleston M, Udayakumara N, Adhikari S, de Silva D, Sheriff MH, Waidyaratne DL: The importance of poisoning vs. road traffic injuries as a cause of death in rural Sri Lanka. PLoS One 2007, 2:e599.

18. Hung YC, Pai L, Kao SY, Chien WC: Characteristics and trends with respect to unintentional drug poisoning mortality and hospitalization in Taiwan, 1999-2008. Taipei City Med J 2010, 7:221-234.

19. Kapur N, Turnbull P, Hawton K, Simkin S, Sutton L, Mackway-Jones K, Bennewith O, Gunnell D: Self-poisoning suicides in England: a multicentre study. QJM 2005, 98:589-597. 
20. Lee HL, Lin HJ, Yeh SY, Chi CH, Guo HR: Etiology and outcome of patients presenting for poisoning to the emergency department in Taiwan: a prospective study. Hum Exp Toxicol 2008, 27:373-379.

21. Law \& Regulations Database of The Republic of China (Taiwan): Drug Relief Act. 2010 [http://law.moj.gov.tw/LawClass/LawAll.aspx?PCode=L0030023].

22. Lee WJ, Cha ES, Park ES, Kong KA, Yi JH, Son M: Deaths from pesticide poisoning in South Korea: trends over 10 years. Int Arch Occup Environ Health 2009, 82:365-371.

23. Henao S, Arbelaez MP: Epidemiologic situation of acute pesticide poisoning in Central America, 1992-2000. Epidemiol Bull 2002, 23:5-9.

24. Thapinta A, Hudak P: Pesticide use and residual occurrence in Thailand. Monit Assess 2000, 60:103-114.

25. Satoh T, Hosokawa M: Organophosphates and their impact on the global environment. Neurotoxicology 2000, 21:223-227.

26. Chen MS, Huang CL: Industrial workers' health and environmental pollution under the new international division of labor: the Taiwan experience. Am J Public Health 1997, 87:1223-1231.

27. Council of Agriculture, Department of Health Executive Yuan, ROC (Taiwan): Agricultural employed population by sex and age. 2010 [http://www.coa. gov.tw/htmlarea file/web_articles/4379/t6.xls].

28. Bureau of Animal and Plant Health Inspection and Quarantine, Council of Agriculture, Department of Health Executive Yuan, ROC (Taiwan): Banned pesticides lists. 2010 [http://pesticide.baphiq.gov.tw/web/ Insecticides_Menultem7_1.aspx].

29. Bose A, Sandal Sejbaek C, Suganthy P, Raghava V, Alex R, Muliyil J, Konradsen F: Self-harm and self-poisoning in southern India: choice of poisoning agents and treatment. Trop Med Int Health 2009, 14:761-765.

Pre-publication history

The pre-publication history for this paper can be accessed here: http://www.biomedcentral.com/1471-2458/11/703/prepub

doi:10.1186/1471-2458-11-703

Cite this article as: Chien et al:: Trends in poisoning hospitalization and mortality in Taiwan, 1999-2008: a retrospective analysis. BMC Public Health 2011 11:703

\section{Submit your next manuscript to BioMed Central and take full advantage of:}

- Convenient online submission

- Thorough peer review

- No space constraints or color figure charges

- Immediate publication on acceptance

- Inclusion in PubMed, CAS, Scopus and Google Scholar

- Research which is freely available for redistribution

Submit your manuscript at www.biomedcentral.com/submit 